Список литературы:

1. Христофоров И.И. Исследование спектральных характеристик электромагнитных сигналов при георадиолокационном зондировании однородного песка различной льдистости / И.И. Христофоров, М.А. Дьячковская, К.И. Бажин, И.И. Федоров, А.Л. Лобанов // ЭРЭЛ-2016: Материалы Всероссийской конференции научной молодежи. Т.1. - Якутск: Издательский дом СВФУ, 2016, С.270-274.

2. Христофоров И.И. Исследование спектральных характеристик сигналов при георадиолокационном зондировании в контакте с электропроводящими средами / И.И. Христофоров // Проблемы горной науки. Взгляд молодых ученых: Материалы научной конференции молодых ученых и специалистов ИГДС СО РАН, посвященной памяти академика РАН Н.В. Черского. - Якутск: Издательство ИМЗ СО РАН, 2013. С. 128-131.

\title{
Влияние концентрации хлорид-ионов на сорбцию урана
}

Хужаев Ж.Э., научный сотрудник,

Суннатуллоев Ш.Ш., магистр,

Навоийский государственный горный институт, 2. Навои, Узбекистан

E-mail: u0505@mail.ru

Научный руководитель: к.т.н. Шарафутдинов У.З.

Навоийском ГМК существующая технология предусматривает извлечение урана методом подземного выщелачивания и дальнейшим выделением из продуктивных растворов на ионообменных смолах. Ее использование обеспечивает избирательное выделение урана из растворов и его концентрирование. При этом основные свойства растворов не изменяются и возвращаются в цикл. В технологии выщелачивания учитывают условия последующей переработки растворов (остаточную кислотность, общее содержание солей и наличие депрессирующих компонентов при сорбции). При сорбционном извлечении урана из растворов используют в основном аниониты. Сопутствующие примеси в продуктивных растворах ведут себя неодинаково. Катионы щелочных и щелочноземельных элементов, ионы меди, железа, кобальта, марганца практически не сорбируются. Сульфат-, нитрат-, хлорид-, фторид- и фосфат-ионы хорошо сорбируются и являются депрессорами. Кроме того, существуют анионы, способные накапливаться на анионитах и «отравлять» их, так как их сродство с последними чрезвычайно прочно. По характеру поведения примесей их можно подразделить на инертные, депрессирующие и отравляющие.

Одновременно, хотя и в меньшей мере, идет конкурентная сорбция присутствующих анионитов: $\mathrm{SO}_{4}{ }^{2-} ; \mathrm{HSO}_{4}{ }^{-} ; \mathrm{Fe}\left(\mathrm{SO}_{4}\right)_{2}{ }^{-} ; \mathrm{Fe}\left(\mathrm{SO}_{4}\right)_{3}{ }^{3-} ;$ некоторых анионных форм V; P; Мо; As; а также $\mathrm{CI}^{-}$и $\mathrm{NO}_{3}{ }^{-}$.

К инертным относятся катионы $\mathrm{Fe}^{+2} ; \mathrm{Mg}^{+2} ; \mathrm{Ca}^{+2} ; \mathrm{Na}^{+} ; \mathrm{K}^{+} ; \mathrm{Cu}^{+2} ; \mathrm{Co}^{+2} ; \mathrm{Sr}^{+2}$; $\mathrm{M}^{+2}$, которые не сорбируются и являются балластными примесями.

Депрессирующими примесями являются, анионы, хорошо сорбируемые анионитами, и конкурирующие с извлекаемым комплексами ионов урана. К анионам 
такого рода относятся сульфат- и бисульфат- ионы; нитрат-; хлорид-; фторид- и фосфат -ионы.

Таблица 1

Зависимость статической обменной ёмкости анионита от рН раствора

Концентрация в исходном растворе: хлорид-ионов 15000 мг/л, металла - 50 мг/л

\begin{tabular}{|c|c|c|c|c|c|c|}
\hline \multicolumn{5}{|c|}{ Концентрация в растворе, мг/л } & \multirow{2}{*}{\multicolumn{2}{|c|}{$\begin{array}{c}\text { Содержание } \\
\text { в насыщенной смоле, } \\
\text { мг/г }\end{array}$}} \\
\hline \multicolumn{3}{|c|}{ До сорбции } & \multicolumn{2}{|c|}{ После сорбции } & & \\
\hline $\mathrm{pH}$ & $\mathrm{Me}$ & $\mathrm{Cl}$ & $\mathrm{Me}$ & $\mathrm{Cl}$ & $\mathrm{Me}$ & $\mathrm{Cl}$ \\
\hline 1,8 & 50,0 & 15000 & 48,5 & 13900 & 0,71 & 102,1 \\
\hline 5,0 & 50,0 & 15000 & 50,0 & 14000 & 0,24 & 101,2 \\
\hline 7,7 & 50,0 & 15000 & 49,0 & 14000 & 0,73 & 101,2 \\
\hline
\end{tabular}

Из литературы [1, стр.129] известно, что хлорид - ионы являются сильнейшим депрессором сорбции урана сильноосновными анионитами.

В табл.1 приведены данные по сорбции урана из продуктивного раствора геотехнологического участка анионитом ВО-020. Сорбцию проводили в статических условиях при объёмном соотношении смола : раствор $=1: 1000$ в течение 24 часов.

Как видно из представленных в табл.1 данных, независимо от $\mathrm{pH}$ раствора уран практически не сорбируется, в то время как ёмкость насыщенной анионита по хлорид иону приближается к теоретически возможной (3 мг-экв /г или 106 мг/г).

Исследовалась также возможность увеличения сорбционной ёмкости анионита путём разбавления исходного продуктивного раствора водой. Исследования проводили как в статических, так и в динамических условиях с использованием лабораторных колонок. Результаты приведены в табл. 2.

Таблица 2

Зависимость ёмкости смолы от разбавления продуктивного раствора

Концентрация в исходном растворе: хлорид-ионов 11700 мг/л, металла - 20 мг/л

\begin{tabular}{|c|c|c|c|c|c|}
\hline $\begin{array}{c}\text { Разбавление, } \\
\text { раствор: } \\
\text { вода }\end{array}$ & $\mathrm{pH}$ & $\begin{array}{c}\text { Концентрация } \\
\text { СІ, г/л }\end{array}$ & $\begin{array}{c}\text { Концентрация } \\
\text { Ме, мг/л }\end{array}$ & $\begin{array}{c}\text { Статическая } \\
\text { обменная } \\
\text { ёмкость, мг/г }\end{array}$ & $\begin{array}{c}\text { Динамическая } \\
\text { обменная } \\
\text { ёмкость, мг/г }\end{array}$ \\
\hline Исх. раствор & 1,7 & 11,7 & 20,0 & 1,4 & 1,4 \\
\hline $1: 1$ & 2,1 & 5,9 & 10,0 & 2,7 & 2,98 \\
\hline $1: 2$ & 2,3 & 3,9 & 6,7 & 2,7 & 2,98 \\
\hline $1: 3$ & 2,4 & 2,9 & 5,0 & 2,7 & 2,98 \\
\hline $1: 4$ & 2,9 & 2,3 & 4,0 & 2,7 & 2,98 \\
\hline
\end{tabular}

Как видно из результатов табл.2, разбавление исходного продуктивного раствора в два раза приводит к повышению ёмкости смолы по урану примерно в два раза. Дальнейшее разбавление не сказывается на ёмкости анионита. Однако полученные значения ёмкости смолы остаются низкими.

Изучалась также сорбция урана из продуктивных растворов с использованием катионитов: сильнокислотного сульфокатионита КУ-2 и слабокислотного карбоксильного катионита D - 5201. Результаты приведены в табл.3,4,5. 
Результаты по сорбции урана катионитами

Концентрация хлорид-ионов 15000 мг/л

\begin{tabular}{|c|c|c|c|c|}
\hline \multirow{2}{*}{$\begin{array}{c}\mathrm{pH} \\
\text { раствора }\end{array}$} & \multicolumn{2}{|c|}{ Катионит D 5201} & \multicolumn{2}{|c|}{ Катионит КУ-2 } \\
\cline { 2 - 5 } & $\begin{array}{c}\text { рМе] в } \\
\text { растворе, мг/л }\end{array}$ & $\begin{array}{c}\text { Ёмкость } \\
\text { катионита, мг/г }\end{array}$ & $\begin{array}{c}\text { [Ме] в } \\
\text { растворе, мг/л }\end{array}$ & $\begin{array}{c}\text { Ёмкость } \\
\text { катионита, мг/г }\end{array}$ \\
\hline 1,6 & 35,0 & - & 35,0 & 0,15 \\
\hline 6,3 & 7,0 & 13,0 & 7,0 & 0,18 \\
\hline
\end{tabular}

Как видно из результатов табл.3-5, катионит КУ - неприемлем для сорбции урана из продуктивных растворов, вследствие низких емкостей. Катионит D - 5201 обеспечивает удовлетворительное значение ёмкости по урану при сорбции из $\mathrm{pH}$-ных сред ( $\mathrm{pH}=6,3)$.

Таблица 4

Зависимость ёмкости катионита КУ -2 от разбавления продуктивного раствора

Концентрация в исходном растворе: хлорид-ионов 15000 мг/л, металла - 35 мг/л

\begin{tabular}{|c|c|c|c|c|}
\hline $\begin{array}{c}\text { Разбавление, } \\
\text { Раствор : вода }\end{array}$ & $\mathrm{pH}$ & $\begin{array}{c}\text { Концентрация } \\
\mathrm{Cl}, \text { мг/л }\end{array}$ & $\begin{array}{c}\text { Концентрация } \\
\text { Ме, мг/л }\end{array}$ & $\begin{array}{c}\text { Статическая обменная } \\
\text { ёмкость, мг/г }\end{array}$ \\
\hline Исх. раствор & 3,2 & 15000 & 35,0 & 0,36 \\
\hline $1: 1$ & 7,8 & 7500 & 17,5 & 0,72 \\
\hline $1: 2$ & 8,4 & 5000 & 11,7 & 0,02 \\
\hline
\end{tabular}

Таблица 5

Зависимость ёмкости катионита КУ -2 от рН продуктивного раствора

Концентрация в исходном растворе: хлорид-ионов 15000 мг/л, металла - 35 мг/л

\begin{tabular}{|c|c|c|c|c|}
\hline $\mathrm{pH}$ & 1,6 & 3,2 & 5,4 & 6,6 \\
\hline Ёмкость, мг/Г & 0,15 & 0,36 & 2,24 & 0,14 \\
\hline
\end{tabular}

Показатели процесса сорбции уран - глубина извлечения, емкость анионита зависят от содержания его в перерабатываемом растворе, характеристике анионита, а также количества в растворе ионов - депрессоров сорбции, таких как, сульфат-, нитрати хлорид- ионы.

Список литературы:

1. Громов Б.В. Введение в химическую технологию урана. - М.: Атомиздат, 1978. - C.336. 